www.jmscr.igmpublication.org

Index Copernicus Value: 79.54

ISSN (e)-2347-176x ISSN (p) 2455-0450

crossref DOI: https://dx.doi.org/10.18535/jmscr/v7i6.176

Journal Of Medical Science And Clinical Research

IGM Publication

An Official Publication of IGM Publication

\title{
Casted post and core and full coverage crown restoration over endodontically treated tooth, Case Report
}

\author{
Author \\ Dr Saad Saeed Alshahrani \\ Consultant in Restorative Dentistry, KFMMC
}

\begin{abstract}
The successful treatment of teeth with substantial damage to the tooth structure not only depends on good endodontic treatment, but also on prompt post endododontic restoration of the tooth after the completion of the same. The primary purpose of the post is to retain a core that holds the definitive prosthesis. A post and core also helps to improve the fracture resistance following RCT when the remaining tooth structure is very less. Keeping in mind, the wide array of post systems available, it is critical to decide the type of post endodontic restoration according to the clinical situation. When a large amount of tooth structure is lost or if an insufficient ferrule is present, a custom cast post and core is indicated. The following case reports depicts the restoration of carious anterior teeth after using custom cast posts followed by PFM crowns.

Keywords: custom cast post, ferrule, anterior teeth, post endodontic restoration, PFM crowns.
\end{abstract}

\section{Introduction}

Grossly decayed endodontically treated tooth with less coronal tooth structure remaining either due to a large pre-existing restoration or an extensive access cavity preparation often poses a challenge while choosing an appropriate post-endodontic restorative material ${ }^{[1]}$. Clinicians always face the dilemma whether to go for a direct/indirect restoration, partial/full coverage crown, also whether to opt for a post or not. There is again a confusion whether to select custom cast/ prefabricated post. According to Franklin Weine, most of the Endodontically treated teeth often failed following root canal treatment owing to poor post endodontic restoration rather than primary endodontic cause ${ }^{[2]}$. Remaining coronal tooth structure following RCT, functional requirements of the tooth, esthetics, age of the patient and the existing periodontal condition have to be kept in mind while choosing an appropriate post endodontic restorative material ${ }^{[3]}$. Endodontically treated anterior teeth with minimal to moderate loss of tooth structure without any discolouration can be restored with composite resin which provides an effective coronal seal and reduces the fracture susceptibility of tooth ${ }^{[4,5]}$. Teeth with intact cingulum/incisal edge and one or two small proximal lesions can be restored with composite resin ${ }^{[6]}$. If the root canal treated tooth is discolored, non-vital tooth bleaching followed by direct or indirect veneers is preferred. In cases of endodontically treated teeth with moderate loss of tooth structure. Anterior teeth with more than 50\% tooth structure loss, post and core followed by full coverage restoration is mandatory ${ }^{[8]}$. A wide variety of post systems are available ranging from traditional cast metal posts to newer fiber posts. The ease of use, less time consumption for fiber 
posts along with the available laboratory and clinical evidence validates the utilization of fiber posts as an alternative to metal posts. It doesn't mean custom cast posts have lost their relevance in today`s clinical practice. They are still a better option in cases where change in the angulation of the core is required and where there is more tooth structure loss. This case report show cases restoration of carious maxillary incisors by custom cast post followed by porcelain fused to metal restorations.

\section{Case Report}

A 43 years old male patient presented to our clinic with the chief complaint of decayed upper right tooth and wanted to get them filled. Patient gave a history of pain in the upper right teeth one year ago which gradually subsided on taking medication. Intra Oral Examination revealed multiple decayed, restored, missing teeth, healthy gingiva, Canine Guided occlusion was present without loss of vertical dimension with adequate overjet and overbite. Radiograph revealed deep dentinal caries with increase in the width of PDL space with negative response to EPT and cold test. Our goal was to treat pulpal and periapical infection, restore the involved teeth to their proper form, function. Biomechanical preparation was done using hand files in a step back technique and intracanal medicament of calcium hydroxide was placed for 1 week. Obturation was completed using gutta percha by lateral compaction technique. custom cast posts and PFM crowns were planned for these teeth.

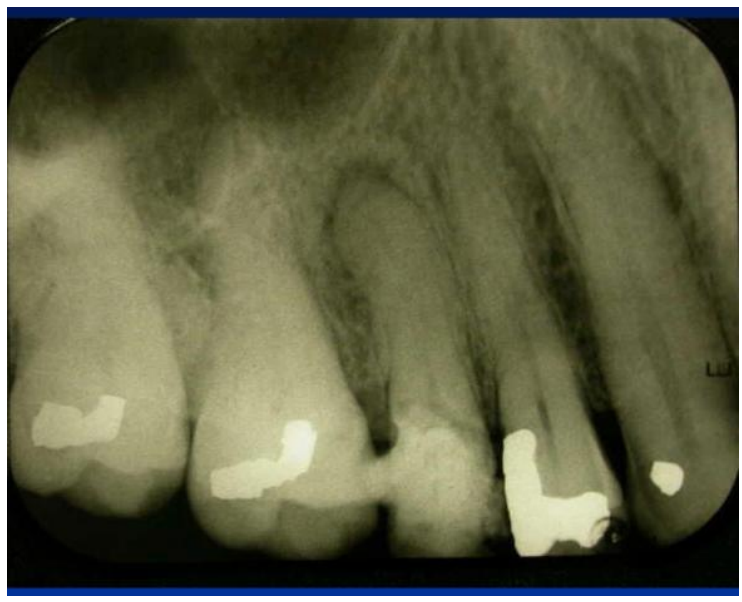

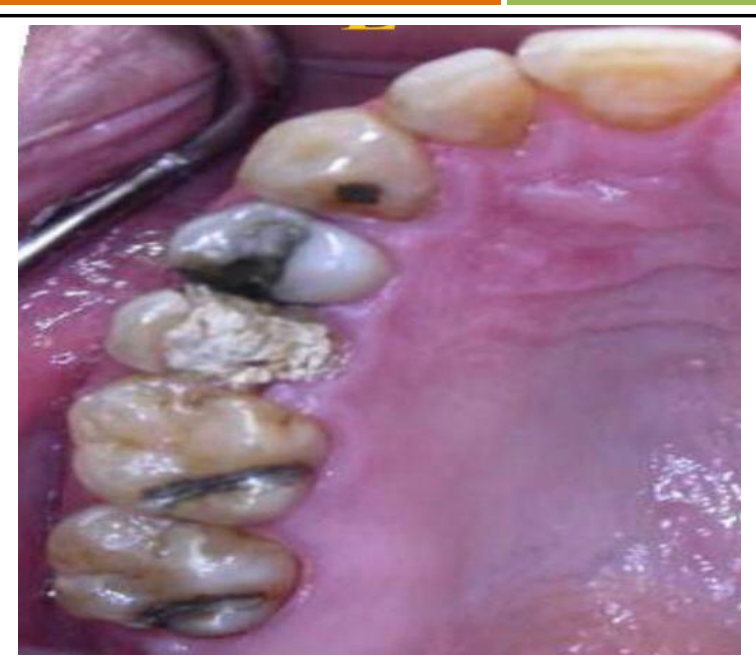

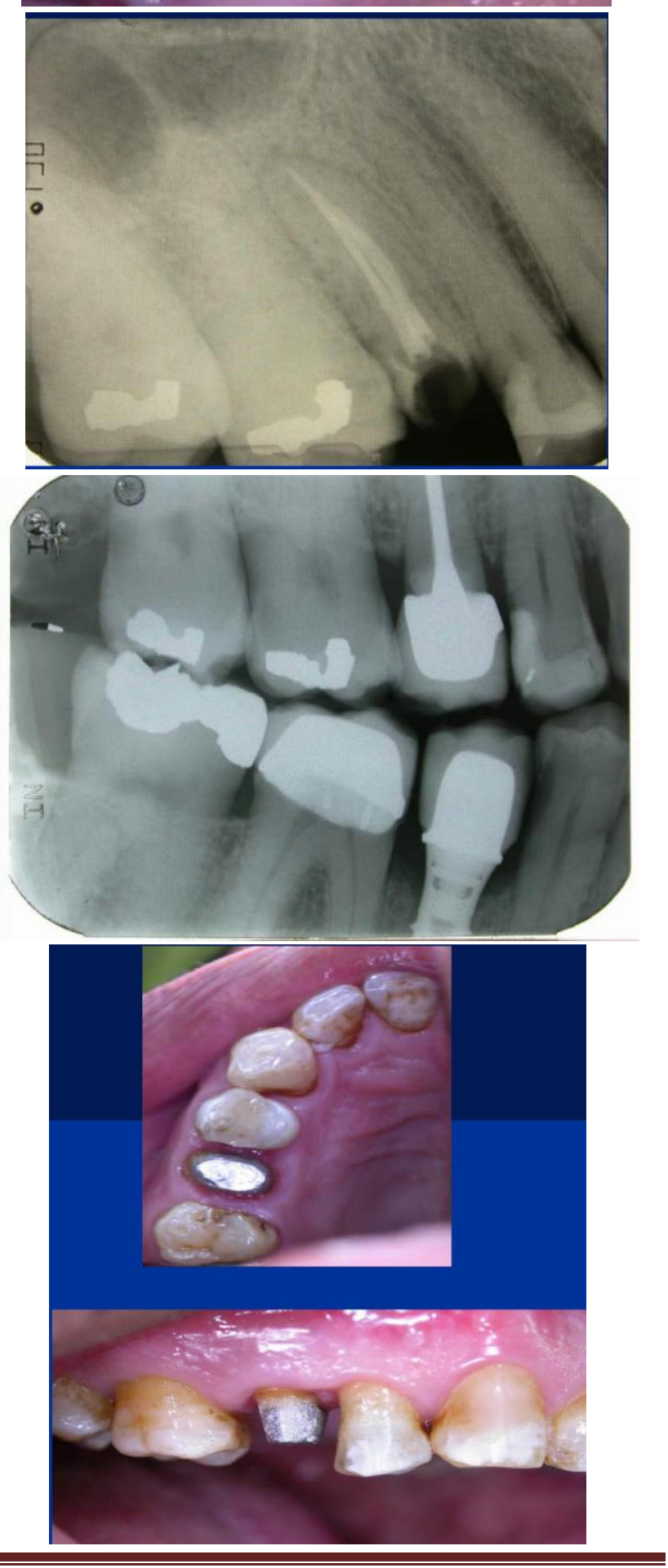

Page 1053 


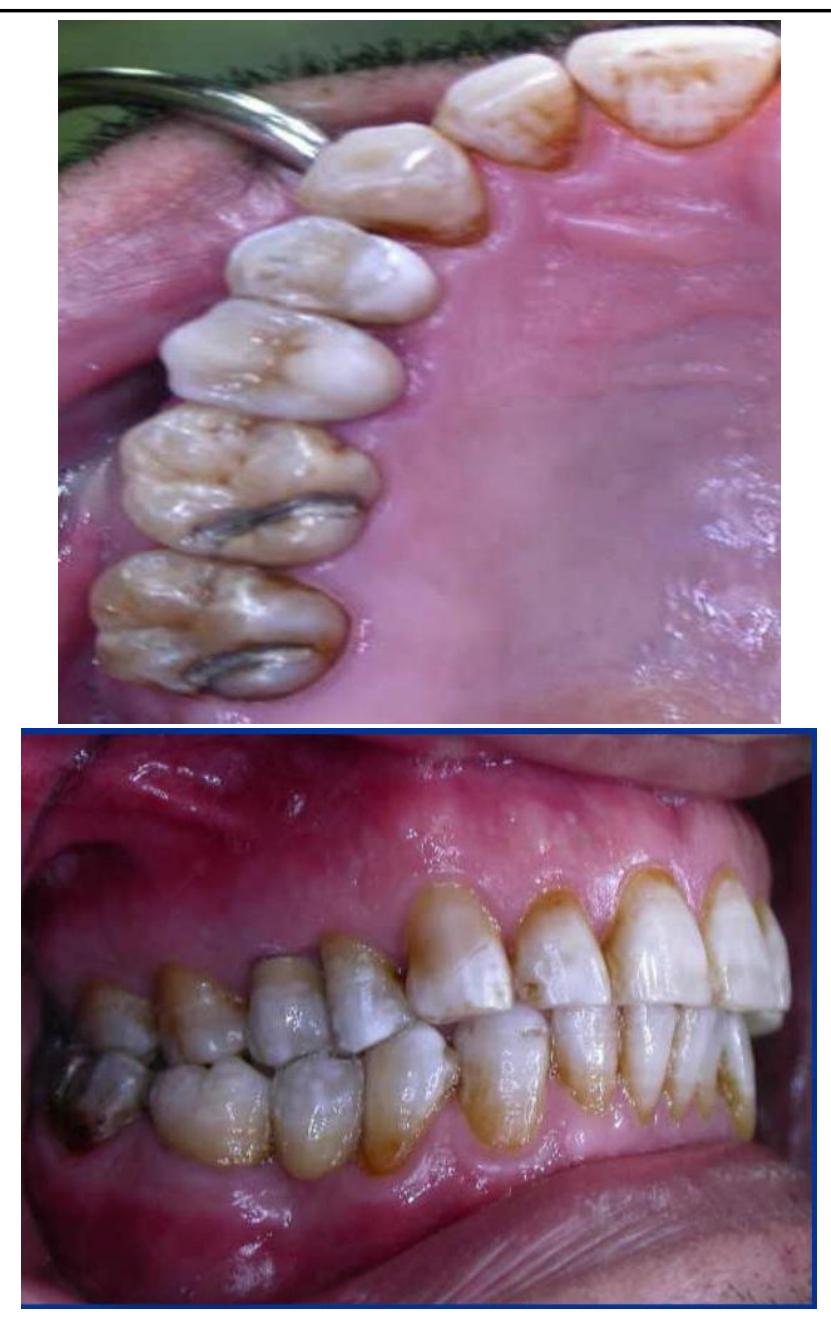

\section{Discussion}

A good post endodontic restoration along with good endodontic treatment often results in healing of periapical inflammation in $91.4 \%$ of the teeth, whereas poor restorations and poor endodontic treatment resulted in the absence of periradicular inflammation by only $18.1 \%$. Furthermore, poor endodontic treatment followed by good permanent restoration resulted in $67.6 \%$ success rate. This clearly showed that success of endodontically treated teeth depended significantly more on the post endodontic restoration rather than quality of endodontic treatment as suggested by Trope and Ray ${ }^{[9]}$. Keeping in mind, the wide array of post systems available in the market and the shift in clinical practice from traditional custom cast posts to prefabricated posts, it is necessary to weigh the advantages and disadvantages of both during treatment planning. Cast posts confirm to the canal morphology and can be used in all types of canal configurations- oval or elliptical. A slight change in core angulation can be done using cast posts and hence they can be used for correcting proclined teeth unlike other prefabricated posts ${ }^{[10]}$. Also, according to Gomez Polo et al, cast metal posts have shown higher survival rates over 10 years $^{[11]}$. According to Santos-Filho PC et al, a $2 \mathrm{~mm}$ ferrule increased the fracture resistance of the endodontically treated incisors, irrespective of crown, core or post type. This may be attributed to an improved stress distribution to the $\operatorname{root}^{[12]}$. According to a systematic review by Rafael Sarkis Onofre et al, posts with high modulus of elasticity performed better ${ }^{[13]}$. In the absence of a ferrule, cast posts with higher modulus of elasticity are preferred, since the amount of tooth structure available for bonding is less and there are no longterm studies on fiberposts to prove the same ${ }^{[14]}$. Fracture resistance of restored teeth and the mode of failure are the result of interaction between multiple mechanical properties and not just the material of the post. However, in certain clinical situations such as in teeth that lack cervical stiffness or in tooth with extensive destruction, with no ferrule or unable to obtain ferrule- cast posts are preferred. Ferrule is the circumferential ring of tooth structure that is enveloped by the cervical portion of the crown. It provides a bracing action to improve the integrity of root canal treated tooth. It allows the crown and root to function as an integrated $\sim 4 \sim$ International Journal of Applied Dental Sciences unit and transmits the occlusal forces to the periodontium physiologically ${ }^{[15]}$. It has also been shown that a $2 \mathrm{~mm}$ ferrule in teeth restored with metal crowns reduced the level of stress concentration in dentin for different metal and non-metal post systems ${ }^{[16]}$. Thus, stiffness of the post and core materials did not appear to significantly influence the strain values and fracture resistance as long as sufficient dentin remained. Also, according to Santos Filho PC et al, it has been reported that the presence of a $2 \mathrm{~mm}$ crown ferrule surrounding remaining tooth structure enhanced fracture resistance of anterior teeth which were restored with a cast post and core and metal ceramic crowns ${ }^{[12]}$. 


\section{References}

1. Burke FJ. Tooth fracture In vivo and in vitro. J Dent. 1992; 20:131-9

2. Franklin S. Weine endodontic therapy. (6th ed.):553-61.

3. Naumann N, Kiessling S, Seemann R. Treatment concepts for restoration of endodontically treated teeth: A nationwide survey of dentists in Germany. J Prosthet Dent. 2006; 96:332-338.

4. Heydecke G, Butz F, Strub JR. Fracture strength and survival of endodontically treated maxillary incisors with approximal cavities after restoration with different post and core systems: an in-vitro study. J Dent. 2001; 29:427- 433.

5. Pontius O, Hutter JW. Survival rate and fracture strength of incisors restored with different post and core systems and endodontically treated incisors without coronoradicular reinforcement. J Endod. 2002; 28:710- 715 .

6. Khirtika SG, et al. J Pharm. Sci. \& Res. 2017; 9(11):2123-2126.

7. Balkenhol M, Wostmann B, Rein C, Ferger P. Survival time of cast post and cores: a 10-year retrospective study. J Dent. 2007; 35:50-58.

8. Cheung W. A review of the management of endodontically treated teeth: post, core and the final restoration. Journal of the American Dental Association. 2005; 136(5):611-619.

9. Ray HA, Trope M. Periapical status of endodontically treated teeth in relation to the technical quality of the root filling and the coronal restoration, International Endodontic Journal. 1995; 28(1):12-18.

10. Bada NZ. Contemporary Restoration of Endodontically Treated Teeth Quintessence Publishing, Hanover Park, Ill, 2013.
11. Gómez-Polo M, Llidó B, Rivero A, Del

Río J, Celemín. A 10-year retrospective study of the survival rate of teeth restored with metal prefabricated posts versus cast metal posts and cores. J Dent, 2010.

12. Paulo Cesar Freitas Santos-Filho. Influence of Ferrule, Post System, and Length on Biomechanical Behavior of Endodontically Treated Anterior Teeth JOE, 2014; 40(1).

13. Sarkis-Onofre, Fergusson, Cenci, Moher. Pereira-Cenci Performance of Post retained Single Crowns: A Systematic Review of Related Risk Factors. J Endod, 2017.

14. Da Silva NR et al. The effect of post, core, crown type, and ferrule presence on the biomechanical behavior of endodontically treated bovine anterior teeth. The Journal of Prosthetic Dentistry. 2010; 104(5):30617

15. Jotkowitz A, Samet N. Rethinking ferrule-a new approach to an old dilemma. $\mathrm{Br}$ Dent J. 2010; 209:25-33

16. Barkhordar RA, Radke R, Abbasi J. Effect of metal collars on resistance of endodontically treated teeth to root fracture. J Prosthet Dent. 1989; 61:676678

17. Ramya Nethravathy, Santhana Krishnan Vinoth, Ashwin Varghese Thomas. Three different surgical techniques of Crown lengthening: A comparative study. J Pharm Bioallied Sci. 2013; 5(1):S14-S16

18. Luis Antonio Felippe, Sylvio Monteiro Jr, Luis Clovis Cardoso Vieira, Elioto Araujo. Re-establishing biologic width with forced eruption. Quitessence Int. 2003; 34(10). 